\title{
KÜLTÜR VE STRES
}

\author{
Zafer íleARs*
}

İnsan yaşamının süreklitiğini șağlayan bilgi, düşünce ve becerileri kuşaktan kuşağa kültür vasıtasıyla aktaran insanoğlu çevresine, üzerinde yaşadığı evrene, giderekte kendisine egemen olmak için sağlığını korumak, refahını sağlamak amacıyla çevresini biçimlendirmekte ve kültürüyle değerlendirip yorumlamaktadır.

Yaşamın bir parçası ve belirtisi olan hastalık insanın atalarından kalma bir olgu olup insanlık tarihi kadar eskidir. Her devirde ve her toplumda hastalığı tedavi etme mücadelesi içinde olan insanoğlu bu mücadeleyi, değer yargılarıyla, inançlarıyla, gelenek-görenekleriyle, dünya görüşũ ve teknolojisiyle yapmaktadir.

Her toplumda hastalık ve sağlığa iliş̧in inanç ve tutumlar farklılık gösterebilir. Bir toplumda tıbbi açıdan patolojik görünen bazi. davranışlar diğer toplumlar için normal bir davranış olarak kabul ediilir.

Çeşitli toplumlarda stresin kültürel görünümleri üzerinde çalışan sosyal antropologlar kültürel etmenlerin, strese tepkide karmaşık bir rol oynadığını saptamışlardır. Genelde bu rol koruyucu yada patolojik olabilir. Kültür, ayrıca stres tepkisinin belirgin bir "huzursuzluk lisanı" kalıbı içerisinde biçimlenmesinede yardımcı olabilir. Aynı

* Prof. Dr. A.U. Sosyal Antropoloji ve Etnoloji Bölüm Başkanı. stres etkenlerine maruz kalan gruplar farklı kültürlerde farklı tepkiler göstermektedirler.

Guthrie ve arkadaşları Fransız, Amerikalt, Filipinli ve Haitili kolej öğrencileri üzerinde yaptıkları araştırmalarda, dört grupta farkı semptom (belirti) oluşumları ile karşılaşmışlardır. Öneğin Amerikalılar'ın organik tepkileri daha çok mide ve bağırsaklarla ilgili septomlar iken Fransızların daha çok davranış ve düşünce tarzı ile ilgili semptomlarda yoğunlaşmıştır. Filipinliler, özellikle kızlar, çarpıntı ve soluk alma zorluğu gibi kalp ve damar rahatsızhı̆ı semptomları göstermişlerdir. Her dört grupta özellikle kızlar arasında baş dönmesi, başağrısı, kabus görme ve kas seyirmesi gibi yakınmalar yaygın olarak görülmüştür. Bu durumda araştırmacıların ulaştıkları sonuç şudur. "Bazı toplumlarda erkeklerin stres semptomlarını kabullenerek açığa vurmaları sosyo-kültürel açıdan daha az kabul edilebilir bir durumdur." Bir grubun kültürel değerleride strese karşı koruyucu etken olabilir. Örneğin, aile birliğini ve beraberliğini güçlendirerek bireyin yaşamının zorluklarıyla başa çıkabilmesini kolaylaştırmak mümkündür. Bir kültürün dünya görüşü, kişisel acıyı genelleştirme yoluyla stresten uzaklaştırabilir. Özellikle dini inançlar, kadercilik, "Tanrı böyle istedi", "Kısmet böyleymiş" veya "Alın yazısı" gibi kaderci görüşler bunun güzel örneklerini oluşturur. Paylaşlan kavramsal bir sisteme sahip bir grubun üyesi olmakta, günlük yaşama anlam ve tutarlılık kazandırarak 
belirsizlikten oluşan strese karşı bir güvence sağlayabilir. Meditasyon ve düşünceye dalma gibi uğraşlara, rekabet ve maddi başarıdan daha fazla değer veren kültürlerin üyeleri genelde strese daha az maruz kalırlar. Değinilmesi gereken bir diğer faktör ise bir çok toplumda çocuk yetiştirmenin (ve bunun getirdiği stresin) geniş aile yapısı içerisinde paylaşılması ve bunun koruyucu bir işlev oluşturmasıdır. Ancak batılılaşmamış veya endüstrileşmemiş topłumlara baktığımızda, Foster ve Anderson'un ileri sürdükleri stressiz "ilkel" varoluş efsanesi deyiminden kaçınmamız gerekir. Dünya sağık teşkilatının (WHO) stresi "modern toplumun psikolojik, sosyal ve ekonomik koşullarında geleneksel uyum sağlama yönteminin yetersiz kalması" şeklinde tanımlamasının aksine, açıkça görülen odur ki geleneksel toplumiarda zararli stres etkenlerinden nasiplerini almaktadırlar.

Kültür bir yandan strese karşı mücadelede olumlu etken olurken, diğer yandan olumsuz etkenlerde yaratabilir. Yani, bazı kültürel inançlar, değerler ve uygulamalar, bireyin maruz kaldiğı stres etkenlerinin sayısını arttırabilir. Hahn ve Kleinman'in ifade ettiği gibi "inanç öldürebilit ve jyleştirebilir'de". Bazı streslerin kaynağı kültür olabilir. Kültürojenik stresde (kültürden kaynaklanan stres) örneğin: Her toplum "başarıyı" (başarısızlığa karşıt olarak), saygınılığı (utanç verici duruma karşıt), "iyi davranış" (kötü davranışa karşıt) kendi değerlerine göre yorumlar ve bu kavramlar farklı toplumlara göre oldukça farklı değerlendirilir. Yeni Gine'nin bazı kesimlerinde, örneğin, özel bazı durumlarda başka kabile üyeleri ile takas edilecek yeterli sayıda domuza veya yeterli miktarda tatli patatese sahip olmamak strese neden olan "utanç verici" bir durum sayılır. Batı dünyasında, tüketim mallarına sahip olmak konusunda komşu jonesler'le aynı düzeyde olmamak, onların yaşam düzeylerine ayak uyduramamak "başarısızlık" sayılabilir'ki bu da öznel stresie sonuçlanabilir. Her toplumda bireyler toplumların belirlediği hedeflere, saygınlık düzeyine veya davranış standartlarına erişmek için uğraşırlar. Saptanan hedeflere ulaşamamak (bu hedefler başka toplumlara saçma gelse bile), bezginliğe, stres tepkisine ve "vazgeçme-vazgeçilme kompleksi" ne yol açabilir. "Karşı konulmaz bir güç tarafından lanetlendiğine" dair inanış gibi bazı inanışlarda, inanan kişi kısa sürede hayatını kaybedebilir. Belirli kişilerle evliliğe zorlanma, savaşcı olma, mal edinme veya saygınlık kazanma yarışı gibi toplumsal ve kültürel dürtülerde diğer stres etkenleridir. Bir toplumda zenginliğin hakça dağılmamış olması fakirler için stres yaratıcı bir unsur oluştururken, ekonomik üstünlüğe sahip olmak durumunda rekabet ve fakirleşme korkusu gibi elkenlerde stres kaynaḡı olabilir. Hahn ve Kleinman, kültürojenik (kültürden kaynaklanan stres) stresi tanımiarken "necobe" -acı veririm (inanç ve umutların kötü etkileri) ve "placebo" -zevk veririm/sevindiririm fenomenlerini örnek olarak vermektedir.

Kültürden kaynaklanan stresin en çarpıcı örneği antropoloğlar tarafından "vudu ölümü" veya "büyü ölümü" olarak adlandırılan, Landy'nin ise sosyo-kültürel ölüm deyimi yeğlediği stres durumudur. Bu fenomene, Latin Amerika, Arrika, Karayip adaları ve Avusturalya dahil dünyanın bir çok yerinde rastlanmakta, 'genelde geleneksel, endüstrileşmemiş toplumlarda görülmektedir. "Büyü ile ölüm" de kişi büyü ile ölmek üzere seçildiğine inanır, hastalanır ve ölür. Kurban ve yakın çevresi ölümcül lanetin üzerlerinde olduğuna bir kez inanmaya görsünler, herkes artık bu sondan kaçış olmadığına inanmaya başlar. Landy'nin ifade ettiği gibi "toplumu temsil eden büyücü tarafından suçlanan ve lanetlerle dolu ayinle suçlunun mahküm edildiği bir işlem artık başlamıştır ve ठ̋üm kısa sürede, çoğu kez 24 ile 48 saat arasında meydana gelir." Fransız Antropolog Claude Levi Strauss bu işlemi daha detayla anlatmaktadır. Toplumunun geleneklerine göre ölüme mankum edildiğinin farkında olan kurbanın ailesi ve arkadaşları da bu inanca katılır ve yavaş yavaş ondan uzaklaşırlar. Zavallı kurbana lanetli olduḡunu, aslında ölü sayıldığını sık sık hatırlatırlar. Gölgeler ülkesine gönderilmesini sağlamak için ayinler yapılır. Ailesinden, sosyal bağlarından gendolarca koparılıp alınan, kendini kanıtladığı būtün aktivitelerden, görevlerden uzaklaştırılan kurban 
bütün bu konbine şiddete boyun eğer, sosyal destekten tamamen ve aniden mahrum kalarak grubun kararına teslim olur. Bir zamanlar haklara ve sorumluluklara sahip canlı bir varlık, korkunun, ayinlerin ve tabunun (yasakların) pençesinde ölü bir adamdir artık.

Bu örnek Engel'in "vazgeçme-vazgeçilme kompleksine" klasik bir örnek oluşturmaktadır. Bu kompleks Engel'e göre, gerek hastalığı ve gerekse ani ölüme zemin hazırlayan bir etkendir. 170 ani ölüm olayına ait raporları irdeliyerek, çoğunda ortak bir nokta bulunmuştur: Olaylar kişinin göz ardı edemeyeceğni şekilde gelişmiş, aşırı duygusallıkla tehdit edici bir hal alarak kişinin geçmişteki deneyimlerini aşmıştır. Kişi artık duruma hakim olamayacağına inanmaktadır. 170 ani ölüm raporunun 10'u mevki kaybı/saygınlık kaybı sonucu gelmiştir. Örneğin önemli pozisyonlara atanmayı bekleyen iki kişi bu beklentileri gerçekleşmeyince aniden öimüşlerdir. "Kültürojenik" ani ölümlerle ilgili çeşitti varsayımlar üretilmiştir. Canon, kurbanın kültürel yönde eli kolu bağlı seçeneksiz kaldığı bir durumda sempatetik sinir sisteminin aşırı faaliyet-gösterdiğine inanmaktadır, ("savaş veya kaç" tepkisi). Engel ise ani ölümleri, zaten kalp-damar hastası olan kişide ani kalp damar tıkanıklarıyla açıklamaktadır. Duyguların yoğuniaştığı ve psikolojik belirsizlik durumlarında sempatetik (savaş-kaç) ve parasempatetik (karşıııkı konuşma-boyun eğme) sistemlerinin her ikisi birden aynı anda uyarılmaktadır. Lex'in görünüşüne göre bu gibi uyarılma "vudu ölümü" ne özgü ani ölümleri'de açıklamaktadır: Sinir sistemi "aşırı gerilmekte/duyarlı hale gelmekte" ve kişi, büyõ sonucu öleceğinin sık sık hatırlatılmasıyla bu durumu daha da ciddileşmektedir, akut parasempatetik sistemin aşırı aktivitesi, veya 'zihinsel' ölümle yũz yūze gelmektedir.

Vudu ölümü/ "büyü ölüm", kültưr kōkenli stres tepkisinin dramatik ve çarpıcı bir örneğidir.

Sonuç olarak diyebilirizki sosyo-kültürel değişme sürecinin yoğun olduğu gelişmekte olan toplumlarda kültür ajanı ya da yenilik taşıyıcısı kimliğini üstlenmiş olan çeşitli uzmanlar, hastalık ve kültürel değerler arasındaki bağın niteliğini bildikleri oranda topluma ve bireylere yardıma olacaklardır.

\section{KAYNAKLAR}

Burkitt D.P. 1973 Some Diseases characteristic of madern Western Civilization. Br. Med J.1.

Cannon W. 1942. Voodoo Death. Am. Antropologist 44

Engel G.Z. 1971. Sudden and rapid death during psychological stress: Folklore or Folk wisdom. Ann. Intern. Med. 74.

Foster G. M. and Anderson B G. 1978
Medical Anthropology, New York wiley.

Lex B.W. 1977. Voodoo death new thoughts on an old explanation. New York Macmillan.

Kleinmen A. 1980. Paterns and Healers in the context of Culture. Berkley. Univ, of California Press.

Kleinmen A, Eisenberg Z. and Good B. 1978. Culture, likness and.Cone: Clinical lessons From anthropologic and crosscultural research. Ann. Intern. Med. 88. 


\begin{tabular}{llllll}
$K$ & $R$ & 1 & $Z$ \\
\hline
\end{tabular}

Kriz Dergisi 2(1): 180-184

\title{
TOPLUMSAL DEĞişiM, KURUMLARIN YENIDEN YAPILANMASI VE RUH SAĞLIĞI
}

\author{
Sema KUT*
}

Toplum kurumsal düzenlemelerin coğrafi ve psikolojik ortamıdır. Toplum ekonomik, politik, din ve aile kurumlarının oluştuğu insanların bu kurumlar etrafında gruplaştığı işbirliği yaptığı, birbirleriyle rekabet ettiği yada çatıştığı yerdir. Bir toplum içinde anlaşılması gereken çeşitli gruplar örgütlenmeler vardır. Toplumun işlevselliği için bütün bunlar arasında etkileşim gerekir. Küçük grup süreçlerini, temel örgütlenme süreçlerini, toplumun yapısını, işleyişini ve değişmesini anlamak gerekir.

Toplum bireyler arasındaki ilişkilerin ve etkileşimlerin oluşturduğu bir bütündür. Bu bütün kendini oluşturan bireylerin toplamından ayri bir varlıktır. Toplumun tümünü temsil eden bu yapı, son derece karmaşık ve çeşitli ilişkiler olarak karşımıza çıkmaktadır. Söz konusu yapı içinde yer alan bu jlişkiler kuşakların birbirini etkilemeleri sonucu süreklilik kazanır. Başka değişle, birey sadece fizik çevresinin değil, sosyal çevresinin de etkisi altında kalır. Insan çevresinin etkisinde kalan ve aynı zamanda kişiliği ile çevresini etkileyen bir varlıktır. Özetle denilebilir ki bir ilişkiler sistemi olarak kavramlaştırılan toplum çok ve aynı zamanda karmaşık ilişkileri içermektedir.

Birey içinde yaşadığı toplum ve bu bütün içinde qrtaya çıkan farklılaşmalardan etkilenerek gelişir

- Prof. Dr. H.Û. Sosyal Hizmetler Yüksek Okulu Müdürü.

ve yaşadığı topluluğa özgü bir örgütlenme yapısı ve toplumsal değerler sistemi içinde yaşar.

Her toplumda intiyaçları karşılamak ve amaçlara ulaşmak üzere toplumsal kurumlar oluşur. Bu kurumların temel görevi sosyal düzen ve kontroldür. Deviet, din, eğitim, politika, hukuk vb. kurumlar toplumsal kontrol çevresini oluşturur. Toplumun en temel kurumu olan aile ise bu toplumsal kontrol çevresi içinde yer alır.

Toplumun diğer bir gerçeği sürekli bir değişim süreci içinde olduğudur. Gelişmenin en temel oggesi olan değişme toplumsal yapıyı, sosyal örgütlenmeyi, toplumsal ilişkileri tutum ve davranışları, deģer sistemini de beraberinde değiştirir. Bu dinamik yapı içinde yaşayan insan değişmenin yarattığı kendisi için olumlu ve bazen olumsuz sarsıntılara maruz kalır. Burada ortaya çıkan uyum sorunu bireyin değişme kapasitesi, yeteneği, arzusu ve istemieri doğrultusunda birey için olumlu ya da olumsuz sonuçlar verir.

Bireyin yaşamında primer çevresi olan ailenin bireye sağladiğı güvence ve sevgi bireyin değişme uyumunda en büyük desteğidir. Ancak aynı değişme sürecini yaşayan aile kurumu da değişimden etkilenmektedir. O nedenle toplumun ailenin karşılaştığı güçlüklerin üstesinden gelebilmesine yardımcl olacak olanakları, hizmetleri ve güvenceyi sağlayabilmesi gerekir. Günümüzde çok hızlı yer aląn deḡişmenin önemli 
unsurları modernleşme, endüstrileşme ve kentleşme süreçleridir. Modernleşme sürecinin özellikleri; iş gücünün tarım sektöründen teknolojik üretime kayması, kentleşme, mobilite'ye dayalı olarak sosyal tabakalaşmanın donması, өğitim ve iletişimin gelişmesi, okur yazarlığın yaygınlaşması kararlarda yaş yerine bilginin ŏne çıkması, rasyonellik, laiklik, değişme ve ferdiyetçilik değerlerinin önem kazanması, sonuç olarak;

- Fatalizme karşı aktivizim,

- Kırsal yaşama karşı kentsel yaşam,

- Düşük düzeyde akrabalık ilişkileri,

- Düşük düzeyde tabakalaşma,

- Yerel iletişim yerine kitle iletişimi,

- Hareketlilik

olarak belirtilmektedir.

Endüstrileşme'nin özellikleri;

- Göç'ün sonucu aile üyeleri arasında ayrilık,

- Nüfusun yer değiştirmesi nedeniyle ailenin bazı öyelerinin gelişme olanaklarına sahip olarak diğerlerinden çok gelişmesi sonucunda sınıf farklılaşması,

- Endüstriyel sistemin geniş aileyi yok etmesi,

- Bireycilik değerinin aile ve küçük gruplar arasındaki yardımlaşmayı ortadan kaldırma kadın-erkek eşitliği değerinin aile ilişkileri ve üretim ve tüketim ilişkilerine yansıması

olarak ifade edilmektedir.

Kentleşme ise,

- Ailenin yer değiştirmesinde genellikle aile reisinin ayrılmassına bağlı olarak eşin rol ve statüsünün değişmesi,

- Kırdan kente nüfus akışı nedeniyle kır ve kentlerde marjinalliğin artması,

- Kır-kent farklılaşmasının giderek ortadan kalkmasi,
- Ozgürlük, bireycilik değerlerinin gelişmesi,

- Sosyal güvenlik sisteminin yaygınlaşması

olarak görülmektedir.

Bugün tüm dünya toplumlarının karşı karşıya kaldığı bu değişimler sosyal kurumların rol ve fonksiyonunu değiştirirken yeni yapılaşmalara da neden olmaktadır. Toplumiarda gözlenen demokratikleşme olgusu, farklı ideolojik tercihlere insan hak ve özgürlükleri bağlamında yeni değer sistemlerinin oluşmasına, tutum ve davranışların yeniden biçimlenmesine ve insani hizmetlerde farklı yakklaşımlara yer vermektedir. Dolayısıyla ruh sağlığı sektörünün politikası da bazı değişikliklere uğramaktadır.

Diğer politika sektörlerinde olduğu gibi, ruh sağlığı politika sektöründe de, politika uygulayıcıları çalışmalarının temelini oluşturacak normatif pozisyonlar geliştirmişlerdir. Bu pozisiyonlar müracaat sahiplerinin ulaşabileceği hizmetlerin çeşitlilik ve miktarını tanımlar. Güvence, sevgi, şefkat, iş başarısı, yaratıcılık, seksüel ihtiyacın karşılanması ruh sağlığını destekler. Fakat bireyler çevreleriyle olumiu bir ilişki kuramamışlarsa bu ihtiyaçlarını karşılayamazlar. Örneğin işsiz kimseler iş başarısı intiyaçlarını karşılayamazlar, çatışmașı olanlar, bağımlılar yada ilişkiterinde başat olanların sevgi intiyaçlarını karşılamaları pek olası değildir. Suç işleme oranı yüksektir.

Bu tür sorunların çözümlenmesinde ruh sağlığı, politikasında kabul gören bir yaklaşım olan ekolojik yaklaşım yararlıdır. Çünkü bu yaklaşım bireyle çevre arasındaki ilişkide odaklaşır. Ruh sağlığı uygulayıcılarının görev aldığı kuruluş ve kurumların esas fonksiyonu müracaat sahiplerine temel ihtiyaçlarını karşılayabilmeleri için çevreleriyle olumlu ilişkiler geliştirmelerinde yardımcı olmaktır.

Stres kavramı ekolojik yaklaşım açısından önemlidir. Stres bireylerin olumlu ilişkiler geliştirememelerinden ve aile içinde, çalışma yaşamında, çevre ortamında doyurucu etkinlikler gerçekleştirememelerinin bir sonucudur. 


\section{EKOLOJIK ÇERÇEVE}

\section{STRES}

Strese maruz kalma olasılığı taşıyanlar

- Belirgin fiziksel ve ruhsal handikapı olanlar,

- Ayırımcılık deneyiminden geçen grupların üyeleri,

- Yoksullar,

- Yıkıcı aile ve bireysel deneyimi olanlar,

- Toplumdan soyutlananlar

- Travmatik kayıplara uğrayanlar,

\section{STRES'IN GÖSTERGELERI}

- Bireysel amaçlar ve çevresel olanaklar arasında tutarsızlık vardır,

- Çevresel ortamda bireyler süreklilik ve güvence deneyimi kazanırlar,

- Birey toplumsal desteğin ve aile görüntüsünün bir parçasıdır,

- Bireyin çevreyi yönetme becerisi vardır,

- İçsel çatışma bireyin toplumu anlamasını ve toplumla ilişki kurmasını engeller,

\section{ÇEVREsel içeriK}

- Çevre çalkantııdır,

- Çevre güvence sağlar,

- Çevre baskıcıdır,

- Çevrenin ana unsurları değiştirilebilir

\section{BIREYSEL NITELIKLER}

- ilişki kurabilme becerileri,

- Bilişsel beceriler,

- Fiziksel sağlik düzeyi,

- Aile ve toplum kaynakları,

- Kişilerarası beceriler,

- Maddesel kaynaklar,

- Sağ kalmak ve yaşamı sürdürebilme becerileri,

- Bireysel amaçlar.

\section{SEÇILMIŞ SONUÇLAR}

- Benlik saygısı duygusu,

- Yeterlilik duygusu,

- Ruhsal ızdirap ya da acı,

- Bireysel planlama ya da ilişki kurma davranışı,

- Uygun yetkinlik,

- Aile, toplumsal ve çalışma rollerini yerine getirmek 
Bu yaklaşım içinde ruh sağlığı alanında çalışanlar insanlara çevrelerini yönetmelerinde, bireyler, kurumlar ve çevreleriyle olumlu iliş̧̧iler kurmalarında, yıkıcı deneyimlerinin üstesinden gelmelerinde, çevreyle başetme yeteneklerini geliştirmelerinde yardımcı olurlar.

Çevresel değişimin sağlanmasında sosyal eylem etkinlikleri, danışmanlık hizmetleri, ekolojik yaklaşımda yer alan programlardır.

Bir başka yaklaşım da geleneksel toplumların insan sorunlarının çözümünde sağladığı destek sisteminin ģağdaş toplumlarda toplumun normalizasyonu kavramı içinde yer almasıdır. Bireyin sosyal ve ruhsal sağlığının sağlanmasını amaçlayan hizmetler, toplumda bakım ve koruma; (social care) rehabilitasyon, ve toplumsal kontrol (Social control) biçiminde örgütlenmektedir. Toplumda bakım ve korunmanın odağında birey yada çevrenin değişimi; rehabilitasyonda bireyin yeni beceri ve güç kazanması ve toplumsal işlevselliğinin devamının sağlanması; sosyal kontrold $\theta$ ise bireyin hak ve özgürlüklerinin kullanılmasında toplumla çatışmamasının sağlanarak toplum düzeninin diğer bir deyişle toplumun öngördöğü sınıflamaların muhatazası vardır. Burada önemli olan bireyin yaşadığ çevreden kopmadan yada toplumdan izole olmadan bozulan ilişkilerinin toplumun desteği ile düzelmesi yada yıkıcı davranışıarının yapıcı davranışlarına dönüştürüimmesidir.

Kurumsallaşmaya karşı bir tepki olarak ortaya çıkan bu yaklaşım ruh sağlığı alanında rağbet gören bir yaklaşım olmuştur. Ruh hastalarının kurumlardan alınıp kendi toplumlarında daha etkili ve insani tedavi edileceklerine inanan bu yaklaşım ABD'de 1950 'lerin ortalarında ortaya çıkmış ve ulusal ruh sağłı̆ı ve toplum merkezleri yasası ile federal bir politika oimuştur. 1963 de çıkarılan Toplum Ruh Sağlığı Merkezleri yasası ile 75000 ve 200000 nüfusu olan toplumlarda federal bütçeden fon veriłmesi öngörülmüş ancak bazı konservatiflerin tepkisi nedeniyle bu fonun sadece inşaat giderleri için kullanılmasına karar verilmiફ̧, 1965 'de çalışanlara yapılan ödemeler de kapsama alınmıştır.
Halen ABD'de Toplum Ruh Sağlığı merkezleri, ruh sağlığı bakımından önemli bir kaynak oluşturmaktadır. Bu merkezler özel psikiyatri hizmetlerinden yararlanamayan ve genellikle sigortalı olmayanlara hizmet vermektedir. Bir fikir vermesi açısından ABD'de 1975 'de ruh sağlığı bozukluğu nedeniyle hizmetten yararlananların $\% 52 ' i$ haftada $100 \$$ 'dan az kazananlardır. Bu merkezler çeşitli ruh sağlığı sorunu olanlara hizmet vermektedir. bunlardan \%13 depresyon, \%21 nevroz $\% 10$ şizofreni, $\% 22$ sosyal uyumsuzlar ve $\% 13$ 'ü çocukluk davranıs bozukluğu olanlardır. Merkezde fulltime çalışanların sadece \%3'ü psikiyatrist, \% 11 'i sosyal hizmet uzmanı ve \%9'u ise psikiyatrik hemşirelerden oluşmaktadır (US President's Commission Report on Mental Health. Vol. 2).

Görüldüğü gibi ruh sağlığı alanında güncelleşen sosyal psikiyatri birey ve çevre etkileşimi temelinde çeşitli meslek ve disiplinierin örtüştügü ve ekip çalışmasının çok gerekli olduğu bir alan olarak ortaya çıkmaktadır. Bu açıdan verilen hizmetlerin örgũtlenmesinde Yarıyol Evleri modeli uygun görülmektedir. Bu model şematik olarak tanımlanmıştır (Bkz. Sył. 184).

Toplumsal değişim süreci içinde sosyal kurumların uğradığı yapısal değişimler çeşitli alanlardaki hizmet politikalarına yeni boyutlar kazandırmakta ve geleneksel yaklaşımların kaçınılmaz işlevlerinde yeni bilgi ve teknolojiler kullanılırken bir takım farklı yaklaşımlar geliştirilmeye çalışılmaktadır. Sosyal psikiyatrinin gelişmesi ruh sağlığı politikasında kuşkusuz yeni hizmet modellerinin oluşturulmasına yol açmış, konunun sadece kurumsal tedavi ile sinırlı kalamayacağı politika, ekonomi gibi diḡer sosyal kurumlar, değer sistemi ve ideolojilerle de ilişkilendirilmiş̧tir. Bu durum kurumsal tedavi için uyarıian fonların azalmasına mevcut teknik bilgi ve teknoloji sayesinde ilaçların geliştirilmesine, gündüz bakım ünitelerinin oluşmasına yol açmışır.

Sosyal psikiyatrinin üzerinde durulması gerekli olan diğer bir boyutu ise sosyo-ekonomik, kültürel ve politik değişmenin hızla yer aldığı günümüz 


\section{Yarıyol Evleri}

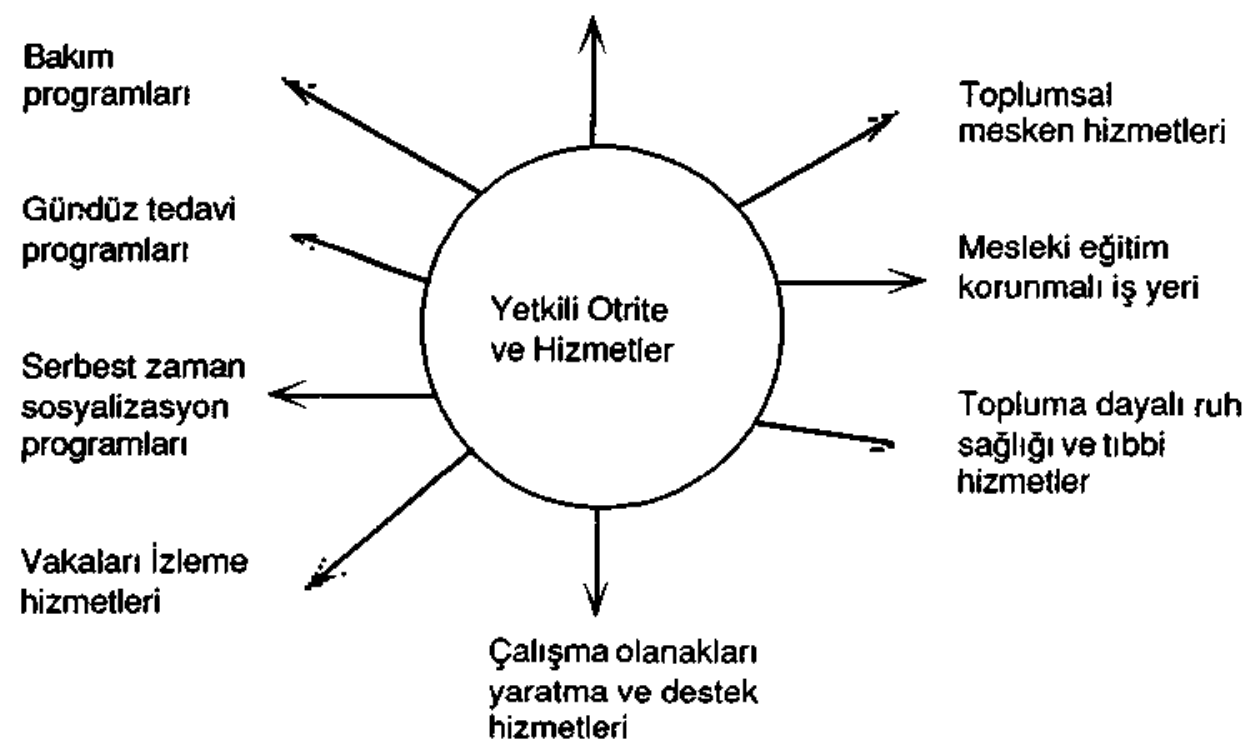

toplumlarında, baş döndürücü gelişmelerin yanı sıra ortaya çıkan değer boşlukları, yeni davranı̧̧ biçimleri, üretim tüketim ilişkilerinin farklılaşması, gelir dağılımın dengesizleşmesi, marjinallik, yoksuliuk, işsizlik, boşanma oranlarının artması, şiddet, etnik gruplaşmalar, vb. bireysel ruh sağlığı açısından önem taşımakla beraber grup eylemleri ve gruplar arası çatışmalar olarak da ortaya çıkmaktadır. O nedenle ruh sağlığı bireysel düzeyden aile düzeyinde, aile düzeyinden grup ve hatta topluluk düzeyinde ele alınması gereken bir konu olmak niteliḡini kazanmıştır.

Sonuç olarak diyebilirizki, değişen toplumlarda ruh sağlığı hizmetlerinin bir takım nüfus gruplarının özel ihtiyaçları, sorunları ve beklentilerine yanıt verecek biçimde düzenlenmelidir. Bu gruplar arasında kadın, düşük gelisliler, etnik ve farklı ırk grupları önem taşımaktadır.

\section{KAYNAKÇA}

Jonsson Bruce Theory and Practice of Social Weltare Poiicy (Belmont California, 1984).

Neugeboren, Organization, Pollicy and Practice in the Human Services (Longman, New York and London 1992).

US President's Commission on Mental Health, Report to the President. 